\title{
80 anos do Serviço Social brasileiro: conquistas históricas e desafios na atual conjuntura
}

\author{
80 years of the Brazilian Social Work: historical \\ achievements and challenges in the current situation
}

\begin{abstract}
Ana Elizabete Mota
Doutora em Serviço Social, professora titular do Departamento de Serviço Social da UFPE/Recife, Brasil.

bmota@elogica.com.br
\end{abstract}

Resumo: Expõe as conquistas históricas do Serviço Social brasileiro nos seus 80 anos de existência. Aponta os desafios da profissão na atual conjuntura e ressalta o significado do Projeto Ético-Político do Serviço Social. Conclui que nas três últimas décadas o Serviço Social ampliou sua função intelectual, contribuindo para a formação da cultura profissional, que se contrapõe à hegemonia das classes dominantes, em orgânica articulação com a esquerda marxista no Brasil.

Palavras-chave: Serviço Social. Cultura profissional. Relativa autonomia profissional.
Abstract: The article presents the historical achievements of the Brazilian Social Work in its 80 years' existence. It shows its professional challenges in the current situation, and it stresses the meaning of its ethical and political project. The article finishes by concluding that, in the last three decades, Social Work has widened its intellectual function, which has contributed to the formation of the professional culture, counteracting the hegemony of the ruling classes, in organic articulation with the Brazilian Marxist left.

Keywords: Social Work. Professional culture. Relative professional autonomy.

\section{Introdução}

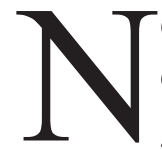

este curto ensaio faço uma síntese - com revisões e acréscimos - do conteúdo da conferência que proferi na mesa de abertura do XV Congresso Brasileiro de Assistentes Sociais (CBAS), intitulada "80 anos do Serviço Social no Brasil”, ocasião em que me reportei à atual conjuntura brasileira, refletindo criticamente sobre suas determinações e particularidades 
e, em seguida, expus as conquistas históricas e os desafios da profissão na atualidade, ressaltando o significado político-profissional do Projeto Ético-Político do Serviço Social brasileiro.

O XV CBAS ocorreu num momento político muito singular no Brasil: o da aprovação pelo Senado Federal, em 31/8/2016, do impeachment da presidenta da República, Dilma Rousseff, materializando um golpe de Estado jurídico-parlamentar e midiático que destituiu a presidenta e empossou o então vice-presidente Michel Temer. Nesse clima de efervescência política, a palavra de ordem "fora Temer" foi aclamada pelas entidades organizativas da categoria e pelos congressistas presentes, dando o tom de agitação política e tática na sessão de abertura do XV CBAS e na manifestação pública que ocorreu no dia 7 de setembro de 2016, em Recife, e da qual participaram mais de 3 mil assistentes sociais.

Por ocasião da referida conferência, recorri a uma formulação de 1995 (Mota, 1995) para afirmar que presenciamos no Brasil, sob novas determinações, a reatualização do que nominei "cultura da crise", cujas diretrizes atuais são a judicialização do poder, a moralização da política e a fetichização dos ajustes fiscais, que desmontam as políticas sociais e subtraem direitos sociais.

Nos anos 1990, a "cultura da crise" (Mota, 1995) foi constitutiva da hegemonia das classes dominantes sob a batuta do Consenso de Washington e das diretrizes emanadas pelo FMI e Banco Mundial, no que se refere à privatização das empresas produtivas estatais e dos serviços públicos, como os de telecomunicações e distribuição de energia, além das reformas previdenciária e trabalhista, abrindo as portas do país ao capital internacional.

A cultura política do momento não opera rupturas com o projeto neoliberal e mercantil do final do século XX. Ao contrário, radicaliza essa ofensiva. Essa radicalização se constitui no substrato da "cultura política da crise do momento", incorporando novas mediações: 1) a desqualificação, pela via moral, das práticas e ideologias do projeto democrático-popular dos governos do Partido dos Trabalhadores (PT), sob a égide do combate à corrupção, conduzida pelo Poder Judiciário, como estratégia de desqualificação política das esquerdas e da política e supervalorização do Poder Judiciário; 2) a ideologização do combate à pobreza através da ampliação da política de assistência social, 
com a criação do Suas. ${ }^{1}$ A centralidade e a hipertrofia da assistência social durante os governos sob a direção do PT, a despeito de reduzirem níveis de pobreza, também foram meios estratégicos de sitiamento de conquistas sociais relativas à propriedade da terra e ao direito ao trabalho; 3) a reificação do acesso ao consumo - responsável pelo surgimento da nova classe média (Luce, 2013) - que dinamizou o mercado interno, endividou e bancarizou os assalariados e proletários através do pagamento de altos juros e taxas bancárias, tornando consensual a ideia de que o acesso a bens mercantis pode ser uma contrapartida à perda de direitos, como foi o caso dos planos de saúde, de previdência privada e compra da casa própria. Tudo isso funcionando como anteparo para a desregulamentação dos direitos do trabalho, privatização do público, manutenção dos compromissos financeiros e pagamento do serviço da dívida pública ao grande capital.

Em suma, na segunda década do século XXI, o aprofundamento da crise do capital, a queda tendencial da taxa de lucros e a hipertrofia do capital financeiro fornecem o lastro para emergir, ressignificada, "a cultura da crise" - uma cultura política levada a efeito pela burguesia e seus intelectuais, referenciada nas diretrizes neoliberais, robustecida pela desqualificação genérica da esquerda, pelo fenômeno da corrupção espetacularizado midiaticamente e pelo conservadorismo moral da direita, ampliando as estratégias materiais e ideológicas necessárias à formação do consenso das classes subalternas.

\section{Breve reflexão sobre a conjuntura em curso}

Em minha opinião, presenciamos o fim de um ciclo de conciliações e consensos levado a cabo nos últimos treze anos pelos governos sob a direção

1. Em ensaio de 2008, intitulado A centralidade da assistência social na seguridade social brasileira nos anos 2000, publicado em $O$ mito da assistência social (Mota, 2008), alertei, em face da ampliação da política de assistência social que chama a atenção, sobre a capacidade que tiveram as classes dominantes em capitalizar politicamente a assistência social, transformando-a no principal instrumento de enfrentamento da crescente pauperização relativa, ampliando o exército industrial de reserva no seio das classes trabalhadoras. Em tal contexto, um dos instrumentos de repolitização da política, como parte da pedagogia da hegemonia, consistiu em definir esse segmento de classe como "excluídos", e os programas de assistência social como estratégia de inclusão. 
do PT, que teve como um dos principais meios de legitimação popular e anteparo para as alianças com a burguesia a bandeira da redução da pobreza e da miséria no Brasil, por meio da criação de políticas sociais, especialmente a de assistência social, sem alterar as condições necessárias ao crescimento e à acumulação do capital privado. A assistência social, em especial o programa Bolsa Família, foi um dos suportes ideológicos do consenso das classes subalternas, no dizer de Silveira Jr. (2016). ${ }^{2}$

Evidentemente que não podemos menosprezar o peso material e social das políticas de redução da pobreza implementadas na última década, a despeito de terem sido tímidas e de não afetarem a reprodução da desigualdade social no Brasil. Embora atendam necessidades reais das classes subalternas, elas também contemplaram interesses de importantes setores econômicos, como foi o caso da construção civil, das obras de infraestrutura, da criação de vagas em universidades privadas, da expansão dos planos de saúde, do crédito ao consumidor, da bancarização dos cartões magnéticos do Bolsa Família etc., sem esquecer os nichos de acumulação sob os auspícios da renúncia fiscal e dos recursos do BNDES que ativaram o mercado interno, ampliaram o consumo e expandiram os empregos.

Aquelas medidas de política social se constituíram no cimento ideológico dos anos do governo sob a direção do PT ao custo de cerca de 2\% do PIB contra os $46 \%$ para pagamento do serviço da dívida, sob o discurso do combate à pobreza, no âmbito da "nova pedagogia da hegemonia", como afirmado por Neves (2005 e 2010).

Penso ser da nossa competência profissional e intelectual politizar e analisar o crescimento dessas políticas, mostrando seus limites, e não apenas a importância de mantê-las, mas, principalmente, a de ampliá-las, conquistando novos direitos e acessos a bens e serviços no âmbito do trabalho, da moradia, da mobilidade urbana, da segurança pública e da seguridade social.

2. Esse estudo afirma que, na supremacia de classe própria da "hegemonia lulista", a assistência social inscreve-se como um dos instrumentos do "consentimento passivo das massas". Tal política colaboraria para o alcance desse "consentimento passivo", tanto através das vantagens materiais implicadas nas transferências de renda, quanto pela influência ideológica que estaria suscitando com sua ação político-pedagógica sobre as camadas pauperizadas por ela alcançadas, além das implicações hegemônicas já colocadas com o "mito da assistência". 
A melhoria de condições de vida de parte da população brasileira, com os programas de transferência de renda e a política de reajuste do salário mínimo, dentre outras, fizeram novos consumidores, mas não uma geração de novos sujeitos políticos. Por isso mesmo, no nosso campo político-profissional e intelectual, devemos identificar quais práticas e ideologias a hegemonia às avessas (Oliveira, 2010) produziu junto às classes subalternas. Com certeza, essa é uma das mediações que inflexionaram as tendências e iniciativas que permitiram à direita exercitar o seu golpe.

$\mathrm{Na}$ conjuntura vivida atualmente no Brasil, as classes dominantes investem na restauração da sua dominação direta, descartando a experiência do "lulismo", malgrado a resistência de importantes setores da esquerda. Vale acrescentar que além de classe dominante, a burguesia quer exercitar a condição de classe dirigente sob o signo do seu projeto de sociedade. Para isso, precisou pactuar, pelo menos até o final do segundo governo Lula, o atendimento de algumas necessidades históricas do subproletariado, cujo apassivamento somente foi estremecido pelas jornadas de junho/2013, quando o confronto entre a esbórnia financeira da Copa e a precariedade das políticas, em especial as de saúde, educação, segurança pública, apresentaram-se como um acinte à sociedade.

Ainda que tenham obtido visibilidade pública, as denúncias das jornadas de junho de 2013 estiveram desconectadas de um explícito projeto de sociedade, apresentando-se como "autônomas" em relação às lutas sociais, aos movimentos organizados e aos partidos. Acenderam a luz amarela da rebeldia genérica e despolitizada, passível de ser instrumentalizada por setores conservadores e vinculados à "nova" direita, imprimindo-lhes (ainda que não exclusivamente) sua direção política conservadora e, por vezes, filofacista (Anunciação de Souza, 2016).

No Brasil, associado ao histórico antirreformismo burguês, iniciativas mundializadas de restauração do capital (Braga, 1996) determinaram a ruptura do "suposto" pacto social-liberal para, mais uma vez, adotar o neoliberalismo (Castelo, 2013) que o social-liberalismo havia amalgamado com tendências social-democratas amesquinhadas. O conservadorismo reformista que as classes dominantes conseguiram com o "lulismo", para tornar palatável o neoliberalismo, hoje é esquecido frente à ofensiva do capital como argumento de 
enfrentamento da crise. Sob os auspícios da cultura da austeridade e governabilidade, valem-se das diretrizes neoliberais para assegurar seus interesses, desregulamentando ainda mais o trabalho, escancarando a economia e as riquezas nacionais ao capital internacional, transformando serviços públicos em negócios, sob o lema do corte de gastos públicos e do livre mercado, para integralizar o processo de capitalização dos serviços, por intermédio das expropriações de direitos e da abertura de novos negócios que inegavelmente foram iniciados na vigência dos governos sob a direção do PT.

A Parceria Transpacífico (TPP), o Acordo de Livre-Comércio Transatlântico (Tafta) e o Acordo sobre o Comércio de Serviços (Tisa) impõem a renúncia do controle da economia nacional em prol, por exemplo, da liberalização do capital estrangeiro na exploração de recursos minerais, na geração de energia, além da criação de negócios na área da saúde, educação, previdência, seguros, transporte aéreo e marítimo, portos, aeroportos, abastecimento de água e infraestrutura básica.

Construindo uma "base social" conservadora, reacionária e, por vezes, filofacista (Anunciação de Souza, 2016), a direita precisou concluir a sua contrarreforma liberal do Estado iniciada nos anos 1990, abater as ideologias do trabalho, as conquistas libertárias das mulheres, as étnico-raciais, LGBT, bem como os embriões de emancipação política (ainda que tênues), dotando seus conteúdos de novos significados em prol da sua direção político-social e moral, cujos principais aspectos, como já referidos, podem ser identificados no combate à corrupção, no fetiche do Judiciário, na austeridade fiscal, no machismo e no branqueamento do poder, para falar nos principais.

Ao que tudo indica, para construir uma vontade coletiva, nacional e popular, as classes subalternas - entendidas no seu mais amplo espectro de composição - terão que se aliar organicamente aos intelectuais impenitentes e aos dirigentes da classe trabalhadora, para reconstruir pedagogicamente a sua própria hegemonia, pautada na defesa da radicalidade democrática, em iniciativas anticapitalistas baseadas em princípios socialistas, na liberdade, na diversidade humana, nos direitos civis, políticos e sociais, bem como na democratização e na socialização da economia e da política, que, diga-se en passant, são diretrizes e princípios explicitados no Projeto Ético-político profissional do Serviço Social. 
É nessa direção que qualifico, no próximo item, os desafios atuais do Serviço Social brasileiro, ciente de que, além dos nossos dilemas profissionais cotidianos e da manutenção das nossas significativas conquistas e capacidade organizativa, a conjuntura atual afeta frontalmente nossa experiência profissional e nos coloca - como, aliás, sempre colocou - , frente à frente com a histórica tarefa de enfrentar, em organicidade com os setores organizados e à esquerda, a agenda regressiva que avança há algum tempo no país.

\section{Conquistas históricas e desafios na atual conjuntura}

Considero o Serviço Social brasileiro uma profissão e uma área de produção de conhecimentos (Mota, 2013 e 2016). A profissão emerge e se particulariza pela intervenção direta e imediata na realidade desde os anos 1940, em compasso com o desenvolvimento do capitalismo no Brasil, em cujo curso as classes sociais fundamentais teceram suas sociabilidades. A sociabilidade das classes dominantes transitou pela modernização conservadora, deslizando da aristocracia latifundiária e agroexportadora para o industrialismo tardio, tendo, na tênue democracia e nos arroubos autocráticos, as mediações das suas práticas sociais, econômicas e ideopolíticas.

As classes proletárias e subalternas, historicamente apartadas dos bens civilizatórios, lutaram e lutam pela sua condição de sujeitos sociais e de direitos contra a exploração do capital e, quando ultrapassam o espaço político-organizativo que lhes é destinado pelas relações sociais capitalistas, recebem as reprimendas político-jurídicas da burguesia e do seu Estado.

Esse desenvolvimento instou a profissão a intervir nas expressões da questão social pela via das políticas públicas e/ou em articulação com iniciativas privadas, confessionais ou laicas. Todavia, nos finais da década de 1970, a luta político-reivindicativa e a organização das classes trabalhadoras requereram do Serviço Social mais do que um saber fazer profissional.

Assim, no período de esgotamento da ditadura civil-militar, a cultura política em andamento à época, protagonizada pela organização sindical, político-partidária e de vários movimentos sociais, propiciou o nosso Congresso da 
Virada (1979), somente possível pela politização e organização dos profissionais do Serviço Social e das instituições de ensino. Esse movimento redundou na reforma curricular de 1982 e, posteriormente, na elaboração dos Códigos de Ética, na lei de regulamentação da profissão e na redefinição do papel político dos conselhos federal e regionais de Serviço Social.

A partir desse ambiente, o Serviço Social fortaleceu sua dimensão político-profissional, seja por determinação das contradições sociais que se acirraram e pelos projetos de classe em confrontos, seja porque o saber fazer profissional já não era suficiente para responder às demandas postas pela complexificação da sociedade brasileira, expressa na dinâmica política dos anos 1980, quando se delineia o amadurecimento de uma direção social estratégica da profissão (Netto, 2004) hoje enfeixada no Projeto Ético-Político profissional.

A profusão de demandas ao Serviço Social foi determinada pelo esgotamento da ditadura civil-militar instaurada em 1964 e pela democratização da sociedade brasileira, quando os movimentos sociais, sindicais e partidários conquistaram direitos inscritos na Constituição federal de 1988. Estas, por sua vez, impuseram novos requerimentos à profissão, relativos ao conhecimento da realidade, aos fundamentos do exercício profissional e às opções ideopolíticas do Serviço Social. À época, esses requerimentos tinham por suposto o conhecimento crítico da realidade, influenciados pelo Movimento de Reconceituação latino-americano e pelo Método $\mathrm{BH}$, em oposição aos documentos modernizantes de Araxá e Teresópolis, numa aproximação ao pensamento marxista e gramsciano, numa década de "euforia democrática" que veio a ser minada, a partir de 1989, pela ofensiva do neoliberalismo, como uma resposta do capital e do seu Estado às conquistas do trabalho desde os finais da década de 1970.

Esta resenha histórica - dirigida especialmente aos jovens profissionais e estudantes ${ }^{3}$ - não passa de um preâmbulo para formular a tese que aqui defendo: nessas três últimas décadas e meia, o Serviço Social ampliou sua função intelectual, como profissão e área de produção do conhecimento, ao construir uma massa crítica de conhecimentos, contribuindo para a formação da cultura profissional - teórica, ética e ideopolítica - que se contrapôs e se contrapõe

3. Ver a síntese de Netto (2016). 
às iniciativas de construção da hegemonia das classes dominantes, em orgânica articulação, a partir dos finais dos anos 1970, com a esquerda marxista no Brasil.

Deve-se lembrar que o Serviço Social brasileiro construiu essa cultura a partir da sua experiência profissional. Nos primórdios da profissão, a sua marca foi a da caridade e filantropia; nos anos 1960 e 1970, a era do desenvolvimento de comunidade e do feitiço da ajuda (Mota, 1998); a partir dos anos 1980, o Serviço Social passa a ser reconhecido pela sua inserção política e intervenção crítico-pedagógica junto aos movimentos sociais, aos processos político-organizativos urbanos e rurais, pela formulação e execução de políticas sociais, e como articulador do exercício de direitos, de conquistas e lutas sociais.

Vale salientar que na primeira década do século XXI, quando da implantação do Suas, houve certa tendência em vincular a atuação dos assistentes sociais à assistência social, como tratou Rodrigues (2007). Hoje, sem perder a condição de um dos principais profissionais da assistência social, o Serviço Social não se restringe a essa política. Ao trabalharem na política de assistência social (refiro-me aos Cras e Creas, entre outros), os profissionais passaram a conhecer e conviver cotidianamente com as mais diversas manifestações da desigualdade e da diversidade humana, vindo a exercitar sua capacidade político-profissional na formulação, proposição e negociação de iniciativas que politizam demandas sociais nos municípios e nos estados, ultrapassando o sentido restrito e os parâmetros dos manuais profissionais elaborados pelo MDS (Silveira Jr., 2016). Esse, aliás, pode ser um paradoxo da hipertrofia da assistência social no cenário das precárias políticas públicas brasileiras.

O legado de rebeldia e resistência nessas últimas três décadas e meia revela o Serviço Social que hoje conhecemos: uma profissão que se insurgiu contra o lugar que as classes dominantes lhe definiram na realidade brasileira - uma sociedade herdeira do escravismo, meritocrática, patrimonialista, machista e conservadora.

Essa trajetória teve e tem filiação teórico-metodológica à matriz marxiana e às lutas sociais de caráter emancipatório, numa explícita aposta na direção ético-política-profissional do Serviço Social, cujo produto - mais do que uma intenção abstrata - expõe, na altura da presente conjuntura, a existência de 
desafiantes ações profissionais, todas mediadas pela precarização das condições de trabalho dos assistentes sociais e pela agenda regressiva que está no horizonte da sociedade brasileira. Certamente, nessa conjuntura, o leque dos fenômenos-objetos trabalhados e pesquisados no âmbito do Serviço Social se ampliará, requerendo problematizações, aportes teórico-metodológicos e conhecimentos da realidade que se refletem e refletirão nas práticas profissionais, no ensino e nos campos de estágios curriculares.

Os espaços profissionais e ocupacionais tradicionais, como saúde, assistência social e previdência, sofrerão reveses e terão atualizadas suas demandas, a abrangência do seu público, as modalidades de intervenção e o conteúdo/racionalização do trabalho profissional. No campo da assistência social, por exemplo, novos segmentos das classes proletárias acorrerão a essa política em função do desemprego; na Previdência Social, já se anunciam outras problemáticas derivadas das relações de trabalho precarizadas e da rigidez de critérios de revisão/definição de benefícios, perícias, seguro-desemprego etc. A saúde, vivenciando um brutal desmonte, também presenciará o crescimento da demanda em função da inadimplência e dos desligamentos massivos de trabalhadores e de suas famílias dos planos e seguros privados de saúde.

$\mathrm{Na}$ área sociojurídica, também são identificadas refrações com a ideologia da judicialização/individualização das lutas, combinadas com a criminalização da pobreza, das drogas, do aborto; ampliação da violência com a população negra, mulheres, crianças, idosos, homossexuais, transexuais, travestis etc., afetando não apenas os direitos sociais, mas os direitos civis e políticos.

Igualmente, as parcerias público-privadas em todos os setores tendem a se ampliar, e na esfera da educação pública, fundamental, técnica e superior, as problemáticas tendem a se aprofundar pelo fato de a ampliação das vagas não vir acompanhada de políticas de manutenção dos alunos, face às precárias políticas de assistência estudantil.

Integra, ainda, o elenco dos desafios os do ensino superior público ou privado com a expansão do ensino mercantilizado, EAD e a interiorização das universidades públicas que foram patrocinadas pelo Reuni, ${ }^{4}$ vindo a constituir

4. Programa de Apoio aos Planos de Reestruturação e Expansão das Universidades Federais. 
uma nova geração de professores e pesquisadores em Serviço Social e que serão afetados pela intensificação do trabalho, pelos cortes na educação e, quiçá, pelo desemprego.

A pontuação dessas demandas ao Serviço Social evidencia as mediações que os processos sociopolíticos operam na realidade brasileira e que se alargarão nesta conjuntura, exigindo que apuremos nossa capacidade intelectual e o espectro de atuação profissional, na perspectiva de tencionar as políticas e os meios de enfrentamento da desigualdade social, sempre levando em conta os limites impostos pela realidade à ação profissional.

Deve-se notar que o Serviço Social brasileiro recolhe do exercício profissional e da relação com a realidade um conjunto de temas e questões que tem capilaridade para além da intervenção profissional propriamente dita, razão, inclusive, de o significado social do Serviço Social não se restringir à dimensão técnico-interventiva.

A minha argumentação é de que o Serviço Social brasileiro não mais se restringe à intervenção imediata sobre a realidade, mas avança rumo a uma intervenção mediata, resultado da sua já referida insurgência em relação à divisão social e técnica do trabalho e do saber; e ao aprisionamento da pesquisa e da produção intelectual às requisições diretas e imediatas do fazer profissional. Essas dimensões - da intervenção mediata e imediata - encerram distinções: enquanto a produção teórico-intelectiva pode não materializar respostas imediatas às demandas da prática profissional, o exercício profissional, por sua vez, se referencia nessa produção, mas mobiliza outras mediações e instrumentalizações que são inerentes ao mundo do cotidiano, das ações institucionais e das condições objetivas sob as quais se dá a efetivação de programas, políticas e projetos sociais. Vale destacar que a profissão é a síntese de várias dimensões: formação profissional, intervenção técnico-operativa, produção de conhecimento, organização política dos agentes profissional, articulados em torno de uma direção social que denominamos de Projeto Ético-Político profissional do Serviço Social.

Qualquer que seja o debate do Projeto Ético-Político - crise ou não crise, viabilidade prática ou ideologia —, o fato é que a sua construção contribuiu decisivamente para a consolidação de ideologias e do ideário profissional do 
Serviço Social, marcados por princípios, valores e referenciais teórico-metodológicos que abraçam a teoria marxiana, a superação da ordem capitalista, o humanismo, o internacionalismo das lutas sociais e a radicalidade democrática, os quais fundamentam, articulam e atravessam a relação entre a realidade e a profissão.

Para além de favorecer, direta ou indiretamente, as condições da prática e da formação profissionais, o Projeto Ético-Político profissional do Serviço Social contribui decisivamente para a consolidação de uma cultura profissional insurgente, rebelde e de esquerda. Podemos dizer, sim, que esse projeto é uma ideologia afirmativa do nosso ethos profissional e que, sob determinadas condições, pode ser tencionado, negado ou revisado - mas sua reafirmação e definição se tornam fundamentais para tecer a unidade do enfrentamento ao projeto político dominante, neste momento de regressão de direitos sociais, políticos e civis, no cenário dos retrocessos golpista, neoliberal, conservador e moralista que imperam no país.

Penso que o Serviço Social brasileiro adensou a sua intervenção na realidade através da construção de uma cultura profissional e intelectual crítica, redefinindo a sua representação intelectual e social até então caracterizada, prioritariamente, pelo exercício profissional, na qual a cultura profissional teve absoluta primazia sobre o estatuto intelectual e teórico da profissão.

Se do ponto de vista da inserção do profissional nos processos e relações de trabalho temos o estabelecimento da relação de controle e subordinação que afeta a condição de trabalhadores(as) assalariados(as), a natureza da relativa autonomia técnica e teórico-política do profissional supõe outras mediações, afora a das relações de trabalho. Referimo-nos à mediação da consciência do sujeito profissional, a uma sólida formação profissional, ao conhecimento das manifestações objetivas da realidade, bem como ao domínio institucional-legal das politicas e dos processos a elas relacionados, cujas competências profissionais para operar sínteses, proposições, articulações e negociações são compatíveis com a permeabilidade socioinstitucional da profissão (Mota, 2014).

$\mathrm{Na}$ ausência dessas competências, ganham projeção a avaliação e o julgamento dos resultados da ação, os quais quase sempre recaem na constatação da impossibilidade de utilização da teoria social crítica, de inspiração 
marxiana, para tratar os fenômenos singulares. Em oposição a essa postura, defendo (Mota, 2014) a necessidade de exercitar a relativa autonomia e reafirmar - como fazem segmentos expressivos da categoria - nossa capacidade de análise da experiência profissional cotidiana, identificando: a) iniciativas que evidenciem posturas que neguem a sociabilidade e a mercantilização do atendimento das necessidades humanas; b) processos de democratização de decisões; c) conquistas e possibilidades do exercício de direitos; d) reconhecimento de sujeitos, reivindicações e lutas sociais que tornam mais concreto o entendimento dos indivíduos e da classe trabalhadora em sua heterogeneidade; e) mediações pedagógicas, éticas e formativas que contribuam para a formação de consciência crítica da população usuária. Em resumo: a identificação de aspectos da realidade que foram ou poderiam ser tencionados pela ação do Serviço Social.

A profissão exercita um movimento em que as situações-objeto da atuação profissional também são objeto do conhecimento e de intervenção política, extrapolando o raio de ação da atividade profissional e expondo a relação com a totalidade historicamente construída, permitindo identificar os nexos entre: a) os objetos da ação profissional e os das lutas sociais; b) a precária e insuficiente oferta de bens e serviços sociais públicos e os processos de privatização e mercantilização das políticas; c) a focalização e a seletividade e os limites da universalização do acesso e dos direitos na sociedade do capital; d) as expressões do desemprego e do trabalho precário, eventual, inseguro e os requerimentos da reestruturação produtiva e da restauração capitalista; e) as mais diversas expressões da pobreza e o conteúdo das modernas expropriações de direito e usufruto de bens públicos não mercantis. Enfim, o trânsito entre o âmbito das singularidades da atuação prático-operativa e as tendências macropolíticas da sociedade brasileira, ou seja, entre os processos de reprodução social e as possibilidades de seu tencionamento, organicamente articuladas a outro projeto de sociedade.

Recebido em 5/10/2016 - Aprovado em 17/10/2016 


\section{Referências bibliográficas}

ANUNCIAÇÃO DE SOUZA, J. M. Tendências ideológicas do conservadorismo. Tese (Doutorado em Serviço Social) — Universidade Federal de Pernambuco, Recife, 2016.

BRAGA, Ruy. A restauração do capital: um estudo sobre a crise contemporânea. São Paulo: Xamã, 1996.

CASTELO, Rodrigo. O social-liberalismo: auge e crise da supremacia burguesa na era neoliberal. São Paulo: Expressão Popular, 2013.

LUCE, Mathias Seibel. A superexploração da força de trabalho no Brasil. Revista da Sociedade Brasileira de Economia Política, São Paulo, n. 32, p. 119-141, jun. 2012.

MOTA, Ana Elizabete. Cultura da crise e seguridade social. São Paulo: Cortez, 1995.

. O feitiço da ajuda: as determinações do Serviço Social na empresa. 4. ed. São Paulo: Cortez, 1998.

. A centralidade da assistência social na seguridade social brasileira nos anos 2000. In: MOTA, Ana Elizabete (Org.). O mito da assistência social: ensaios sobre Estado, política e sociedade. São Paulo: Cortez, 2008.

. Serviço Social brasileiro: profissão e área do conhecimento. Katálysis, Florianópolis, v. 16, n. spe, p. 17-27, 2013.

. Espaços ocupacionais e dimensões políticas da prática do assistente social. Serviço Social \& Sociedade, São Paulo, n. 120, p. 694-705, dez. 2014.

. Serviço Social brasileiro: insurgência intelectual e legado político. In: SILVA, Maria Liduína de Oliveira e (Org.). Serviço Social no Brasil: história de resistências e de ruptura com o conservadorismo. São Paulo: Cortez, 2016.

NETTO, José Paulo. Ditadura e Serviço Social. 7. ed. São Paulo: Cortez, 2004.

NEVES, Maria Lúcia W. (Org.). A nova pedagogia da hegemonia: estratégias do capital para educar o consenso. São Paulo: Xamã, 2005.

. Direita para o social e esquerda para o capital: intelectuais da nova pedagogia da hegemonia no Brasil. São Paulo: Xamã, 2010. 
OLIVEIRA, Francisco. Hegemonia às avessas. In: ; BRAGA, Ruy; RIZEK, Cibele (Orgs.). Hegemonia às avessas. São Paulo: Boitempo, 2010.

RODRIGUES, Mavi Pacheco. Assistencialização da seguridade e do Serviço Social no Rio de Janeiro: notas críticas de um retrocesso. Serviço Social \& Sociedade, São Paulo, v. 91, p. 108-122, 2007.

SILVEIRA JR., A. A assistência social e as ideologias do social-liberalismo: tendências político-pedagógicas para a formação dos trabalhadores do Suas. Tese (Doutorado em Serviço Social) — Universidade Federal de Pernambuco, Recife, 2016. 